\title{
Evaluation of collateral network near-infrared spectroscopy during and after segmental artery occlusion in a chronic large animal model
}

\author{
Konstantin von Aspern, MD, a,b Josephina Haunschild, MD, ${ }^{\mathrm{a}, \mathrm{b}}$ Martin Ziemann, ${ }^{\mathrm{b}}$ \\ Martin Misfeld, MD, PhD, ${ }^{\mathrm{a}}$ Friedrich W. Mohr, MD, PhD, ${ }^{\mathrm{a}}$ Michael A. Borger, MD, PhD, ${ }^{\mathrm{a}}$ and \\ Christian D. Etz, MD, PhD ${ }^{a, b}$
}

\section{ABSTRACT}

Objective: Ischemic spinal cord injury remains the most devastating complication after open and endovascular aortic repair. Collateral network near-infrared spectroscopy has been introduced to noninvasively monitor real-time spinal cord oxygenation. In view of recent advancements in endovascular treatment and minimally invasive staged preconditioning before aortic repair, this study sought to evaluate collateral network near-infrared spectroscopy during and after segmental artery occlusion in a chronic porcine model.

Methods: Surgery for segmental artery occlusion was performed in 12 juvenile pigs, and bilateral lumbar collateral network near-infrared spectroscopy was recorded. Two intervention groups were designed: Group 1 received subtotal segmental artery occlusion (mimicking reimplantation of crucial segmental arteries with patent $\mathrm{T} 12 / \mathrm{T} 13, \mathrm{~N}=5$ ), and group 2 received total occlusion (T4-L5, $\mathrm{N}=7$ ). Pigs were monitored over 3 days.

Results: All animals were paraplegic during the first 24 hours. The subtotal occlusion group completely recovered, whereas $57 \%$ of the total occlusion group remained paraplegic $(\mathrm{N}=4 / 7)$. After segmental artery occlusion, collateral network near-infrared spectroscopy decreased from $92.3 \% \pm 8 \%$ of baseline to $69.3 \% \pm 18 \%$ after 10 minutes in the subtotal group $(P=.003-.017)$ and from $90.1 \% \pm 4 \%$ to $58.2 \% \pm 9 \%$ in the total group $(P<.001-.008)$. Throughout the postoperative period, collateral network near-infrared spectroscopy in the total occlusion group remained lower compared with the subtotal group $(<30 \%$ baseline threshold, $P<.05)$. Lumbar collateral network near-infrared spectroscopy and neurologic outcome were significantly correlated $(\mathrm{R}=0.7, P<.001)$.

Conclusions: Lumbar collateral network near-infrared spectroscopy reacts to occlusion of segmental arteries and correlates with neurologic outcome. The preliminary data suggest that collateral network near-infrared spectroscopy may be a valuable noninvasive tool for detecting imminent spinal cord ischemia during and after aortic procedures involving segmental artery occlusion. (J Thorac Cardiovasc Surg 2019;158:155-64)

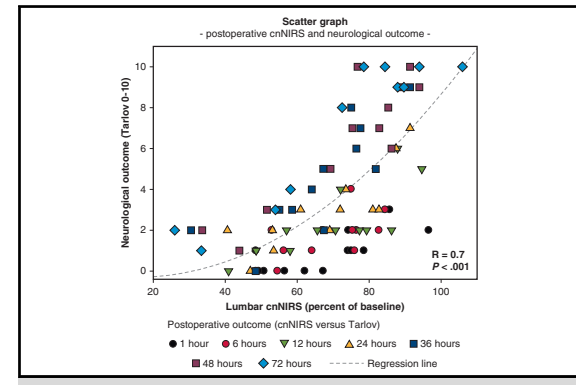

Scatter graph for cnNIRS and neurologic outcome showing significant positive correlation.

Central Message

cnNIRS reacts to SA occlusion. It correlates with neurologic outcome and is lower in total compared with subtotal occlusion.

\section{Perspective}

Lumbar cnNIRS may be a valuable noninvasive tool for detecting pending spinal cord ischemia during and after aortic procedures involving SA occlusion. Further in-depth analyses are warranted to determine the exact threshold for imminent SCI with regard to absolute cnNIRS values.

See Commentary on page 165.

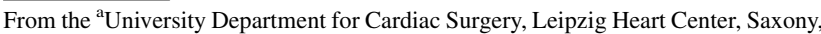
Germany; and ${ }^{\mathrm{b}}$ University of Leipzig, Saxonian Incubator for Clinical Translation, Saxony, Germany.

The presented work is part of the Heisenberg focus project Spinal Cord Protection for aortic surgery (German Research Foundation/DFG)

K.v.A. and J.H. contributed equally to this study.

Received for publication May 9, 2018; revisions received Nov 25, 2018; accepted for publication Nov 26, 2018; available ahead of print Jan 25, 2019.

Address for reprints: Konstantin von Aspern, MD, Department of Cardiac Surgery,

University Heart Center Leipzig and Saxonian Incubator for Clinical Translation,

Struempell Strasse 39,04289 Leipzig, Germany (E-mail: Konstantin_vonAspern@

Uni-Leipzig.de).

$0022-5223 / \$ 36.00$

Copyright (c) 2018 by The American Association for Thoracic Surgery

https://doi.org/10.1016/j.jtcvs.2018.11.105
}

Ischemic spinal cord injury (SCI) remains the most devastating complication after repair of thoracoabdominal aortic aneurysm (TAAA). ${ }^{1,2}$ Despite contemporary perioperative

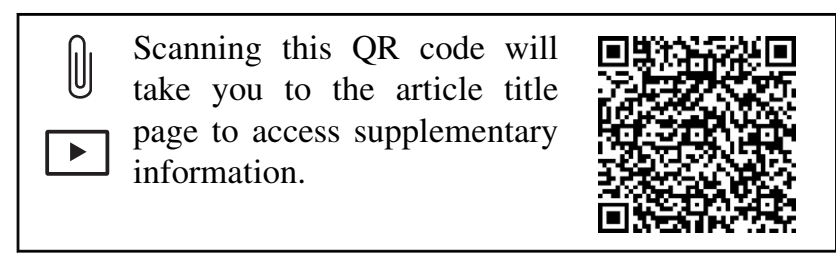




\section{Abbreviations and Acronyms \\ $\mathrm{CN}=$ collateral network \\ cnNIRS $=$ collateral network near-infrared spectroscopy \\ MAP $=$ mean arterial pressure \\ $\mathrm{MIS}^{2} \mathrm{ACE}=$ minimally invasive staged segmental artery coil and plug embolization \\ SA $\quad=$ segmental artery \\ SCI $=$ spinal cord injury \\ TAAA $=$ thoracoabdominal aortic aneurysm}

and postoperative adjuncts, the incidence of paraplegia and paraparesis due to SCI after extensive open and endovascular aortic repair (Crawford type II) remains up to $18 \%$ in large contemporary series. ${ }^{1,3}$ In addition to the individual tragedy for the patient, postoperative paraplegia also represents an immense socioeconomic burden. ${ }^{4}$

\section{MATERIALS AND METHODS \\ Monitoring the Spinal Cord}

Few modalities exist to monitor the spinal cord. Common invasive methods of intraoperative spinal cord viability monitoring include motorevoked potential and somatosensory-evoked potential. ${ }^{5,6}$ Although somatosensory-evoked potential monitoring can be implemented during the postoperative period, motor-evoked potential monitoring on the awake, nonsedated patient is limited. ${ }^{7,8}$ Nevertheless, these modalities usually require significant technical and human resources. Ideally, spinal cord monitoring should reflect perfusion and ultimately tissue oxygenation in real-time to allow for rapid response in hemodynamic (mean arterial pressure [MAP]), cardiopulmonary (atrial fibrillation, ventilation), and cerebrospinal fluid management.

\section{Collateral Network Concept}

The collateral network $(\mathrm{CN})$ corresponds to an extensive arterial networklargely localized in the paraspinal musculature - fed by branches of the subclavian arteries, hypogastric artery, and directly from aortic segmental arteries interconnected via collaterals both longitudinally and horizontally. These collaterals enable sufficient blood flow to the spinal cord tissue during chronic or acute perfusion loss after extensive segmental artery (SA) sacrifice. ${ }^{9,10}$

\section{Collateral Network Near-Infrared Spectroscopy}

Collateral network near-infrared spectroscopy (cnNIRS) has been experimentally and clinically introduced and evaluated for noninvasive (indirect) real-time monitoring of spinal cord perfusion and oxygenation in open TAAA repair. ${ }^{11-13}$ The rationale for cnNIRS is based on the idea that according to the $\mathrm{CN}$ concept, blood supply to and oxygenation in the paraspinal vasculature correlate with spinal cord perfusion and oxygenation.

Our previous clinical and experimental studies have shown that cnNIRS is technically feasible and that lumbar readings correlate with spinal cord perfusion and oxygenation during and after aortic crossclamping and reperfusion. ${ }^{11,12}$ Contemporary data also suggest that high thoracic cnNIRS (T5-T6/7) does not depict changes in regional oxygenation during distal aortic interventions. ${ }^{11,12}$

\section{Study Aim}

Considering the recent introduction of minimally invasive staged SA coil and plug embolization (MIS ${ }^{2} \mathrm{ACE}$ ) for $\mathrm{CN}$ preconditioning before
TAAA repair for paraplegia prevention, ${ }^{6,14,15}$ real-time spinal cord oxygenation monitoring becomes increasingly important, particularly because clinical observation of the awake patient represents the only monitoring method during these procedures.

The aim of this study was to evaluate cnNIRS during and after SA occlusion, focusing on its capability to differentiate between complete and incomplete SA sacrifice and correlation with postoperative neurologic outcome. For this purpose, a chronic large animal model has been designed. ${ }^{16}$

\section{MATERIALS AND METHODS Ethics Statement}

The chronic experimental animal studies were approved by the Institutional Animal Care and Use Committee in accordance with the local Veterinary Office and the Principles of Laboratory Animal Care. ${ }^{17}$ An experienced veterinarian was present throughout the experiments.

\section{Preoperative Preparation and Monitoring Set-up}

Twelve juvenile female pigs (German Landrace, $36-45 \mathrm{~kg}$ ) were lodged in groups for 5 days preoperatively to acclimate. Animals were examined thoroughly with regard to their physical and neurologic condition. Neurologic assessment was performed according to a modified Tarlov score ${ }^{16}$ (Table E1).

On the day of the operation, the pigs were sedated before being transferred to the operating room. After preoxygenation, anesthesia was supplemented by fentanyl (0.03-0.05 mg/kg fentanyl; Pfizer, New York, NY), and after endotracheal intubation, inhalative isoflurane $(1.5 \%)$ was administered. Continuous arterial blood pressure monitoring was established via the left femoral artery. Mechanical ventilation was set to $50 \%$ oxygen at 20 breaths per minute with a tidal volume adjusted at $8 \mathrm{~mL} / \mathrm{kg}$. Body temperature was maintained at $37^{\circ} \mathrm{C} \pm 1.5^{\circ} \mathrm{C}$. Central venous catheterization of the left jugular vein was performed using a 7F, 20-cm multilumen catheter for additional infusions and blood sampling. The pig was then placed on its right side.

\section{Near-Infrared Spectroscopy of the Collateral Network}

After shaving of the animal, lumbar cnNIRS optodes were cutaneously placed bilaterally at level L2 to L3. Preliminary experiments have shown that in nonpigmented, shaved pigs weighing less than $55 \mathrm{~kg}$, cnNIRS measurements during ischemia-reperfusion and baseline are not significantly different regarding cutaneous versus subcutaneous optode placement $(P=1.000)$. Near-infrared spectroscopy signals were continuously recorded using an interface device for noninvasive monitoring of regional tissue (muscle) oxygen saturation of hemoglobin as the ratio between deoxygenated hemoglobin and the sum of deoxygenated and oxygenated hemoglobin (INVOS Oximeter 5100C; Medtronic, Dublin, Ireland). Baseline lumbar cnNIRS values were acquired after preoxygenation and intubation at standard ventilator settings with fraction of inspired oxygen of 0.5 .

\section{Surgical Approach}

Through a lateral thoracotomy via the fifth and ninth intercostal space, the descending thoracic aorta was visualized, and the segmental arteries (SAs) T4 to T13 were exposed. A catheter was introduced into the proximal descending aorta for invasive arterial blood pressure monitoring. An additional catheter was placed into the left atrium. For pressure monitoring, blood sampling and medication administration during the postoperative period catheters were channeled through the fifth intercostal space and subcutaneous tissue and fixated between the shoulders. Abdominal access and exposition of the abdominal aorta and lumbar SAs were achieved via a longitudinal incision. 


\section{Intervention Groups}

Previous studies have demonstrated that the most prominent ischemic spinal cord tissue damage after serial SA occlusion occurs between the lower thoracic (T9/10) and upper lumbar (L2/3) segmental levels. ${ }^{16,18}$ During open TAAA repair, many centers perform reimplantation of crucial segmental arteries located in this area. To explore the influence of patent perfusion in this region on lumbar cnNIRS-via segmental arteries located centrally at level T12/T13-2 intervention groups were designed. Group 1 received consecutive SA closure with complete lumbar occlusion but patent SAs at levels T12/13 (subtotal, $\mathrm{N}=5$ ). Group 2 received consecutive occlusion of all SAs $(N=7)$ (Figure 1). One animal was originally intended for subtotal occlusion; however, because of an aortic tear and bloody oozing, 2 pairs of SAs at the lower thoracic level needed to be ligated in short succession to avoid blood loss and prolonged ventilation. Because this animal ultimately had all SAs occluded, it crossed over to the total occlusion group (verified during autopsy).

\section{Experimental Sequence and Monitoring Procedure}

Consecutive serial occlusion of the exposed SA (pairs) was performed using vessel clips (Titanium Clips, Teleflex Medical, RTP, Morrisville, NC). Starting from SAT4, occlusion was performed in the caudal direction until L5. MAP (aorta + left femoral artery) and lumbar cnNIRS oxygenation were continuously recorded. Regular arterial blood samples were drawn at 10-minute intervals while continuous oxygenation monitoring via pulse oximetry was recorded. The cnNIRS monitoring system stored oxygenation measurements at 5-second intervals. After SA occlusion, the animals remained sedated in a right-sided position for 2 additional hours at identical ventilator settings to ensure standardized cnNIRS measurements. During this period, drainage tubes (thoracic and abdominal) were placed and wound closure was performed. During the entire procedure, no vasoactive drugs were administered.

\section{Postoperative Monitoring and Neurologic Assessment}

After extubation and transportation from the operating room to the animal housing facility, blood samples and measurements of invasive arterial blood pressure, core temperature, peripheral oxygenation, and lumbar cnNIRS were recorded hourly by a physician until 8 hours postoperatively. Afterward, arterial blood pressure and blood samples were recorded at 6hour intervals. Clinical outcome and neurologic evaluation were assessed every 12 hours. Animals were observed for 72 hours. Neurologic recovery was defined according to previous studies ${ }^{18,19}$ as a modified Tarlov score greater than 5 and permanent paraplegia/paraparesis 5 or less, respectively. After the experiments were completed, the animals were anaesthetized and euthanized in deep sedation. The spinal cord was removed en bloc immediately after euthanasia before correct catheter placement and SA occlusion was confirmed, and the autopsy resumed.

\section{Histopathologic Evaluation}

All spinal cords were harvested, and samples from each cord level (identified by nerve root) collected. Evaluation of ischemic cell injury was performed independently and blinded by 2 experienced researchers as previously described and illustrated (Table E2). ${ }^{16,18}$
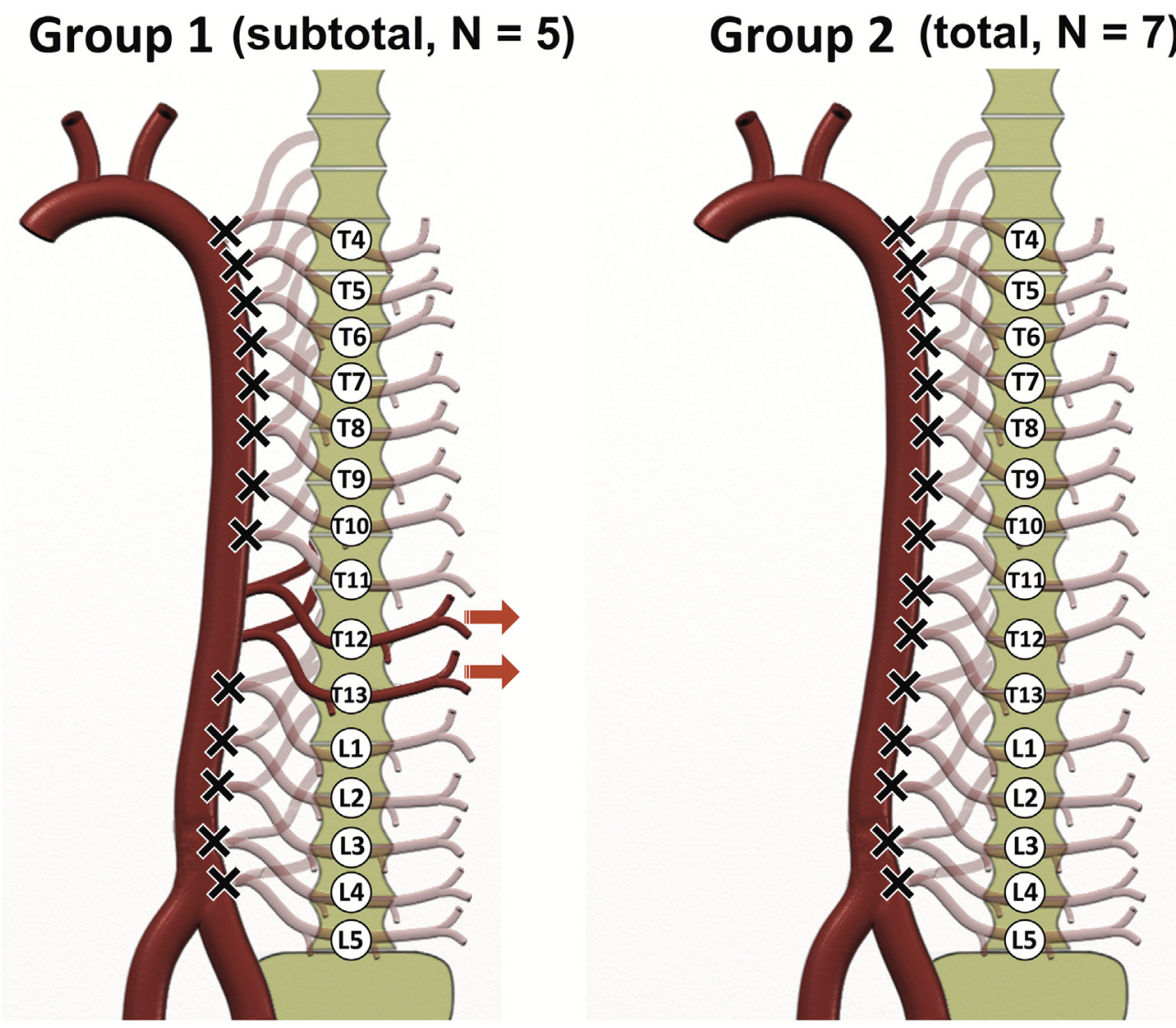

FIGURE 1. Subtotal (group 1) = consecutive SA occlusion with patent perfusion of T12 + T13, total (group 2) = complete SA occlusion T4-L5. 


\section{Statistical Analysis}

Data were imported to SPSS (version 17.0; SPSS, Chicago, Ill) for description and analysis. Continuous variables are expressed as mean \pm standard deviation. Normal distribution of measurements was determined using the Shapiro-Wilk test, and Q-Q plots were created for verification. Group comparison of lumbar cnNIRS and spinal cord tissue was performed using analysis of variance or Student $t$ test for repeated/ correlated measures as appropriate. For correlation analysis, scatter plots were calculated and evaluated using the Spearman's rank correlation coefficient.

\section{RESULTS}

\section{Clinical Outcome and Paraplegia Rate}

Immediately after the operation all animals-subtotal and total occlusion - presented with severe hind limb motor function loss (modified Tarlov score $\leq 2$ ) for the first 12 hours and 5 or less until 24 hours after surgery. All animals in the subtotal group recovered within 48 hours (median score at 48 hours $=9$; range, 8-10), whereas animals in the total occlusion group needed more time for neurologic recovery (median score at 48 hours $=6$; range, $1-8$; $P=.023)$. The rate of permanent paraplegia/paraparesis in group 2 (total) was $57 \%(\mathrm{~N}=4)$. Other adverse events throughout the experiment are listed in Table E3.

\section{Lumbar Near-Infrared Spectroscopy Measurements}

Analysis of variance between left and right cnNIRS measurements did not show systematic differences $(P=1.000)$; therefore, the 2 results were averaged to provide a mean estimate of changes.

Collateral network near-infrared spectroscopy during subtotal segmental artery occlusion (group 1). During serial SA occlusion of T4 to L5-sparing SA T12/13cnNIRS remained stable throughout thoracic SA occlusion, but rapidly decreased from $92.3 \% \pm 8 \%$ of baseline to $77.8 \% \pm 9 \%, 72.4 \% \pm 10 \%$, and $69.3 \% \pm 14 \%$ at 1,5 , and 10 minutes after SA occlusion, respectively $(P=.003-.017)$. Within 1 hour after surgery, cnNIRS values increased to $76.0 \% \pm 10 \%$, fluctuating during the first 24 hours-reaching minimum values of $71.2 \% \pm 11 \%$ at 6 hours and maximum values of $79.5 \% \pm 10 \%$ at 12 hours postoperatively - before steadily increasing to stable values of $86.0 \% \pm 6 \%$ and $89.5 \% \pm 9 \%$ on days 2 and 3 , respectively (Figure 2, group 1/black, and Table E4).

Collateral network near-infrared spectroscopy during total segmental artery occlusion (group 2). Analogous to group 1 (subtotal), complete SA occlusion led to a significant, yet more pronounced reduction in cnNIRS with mean

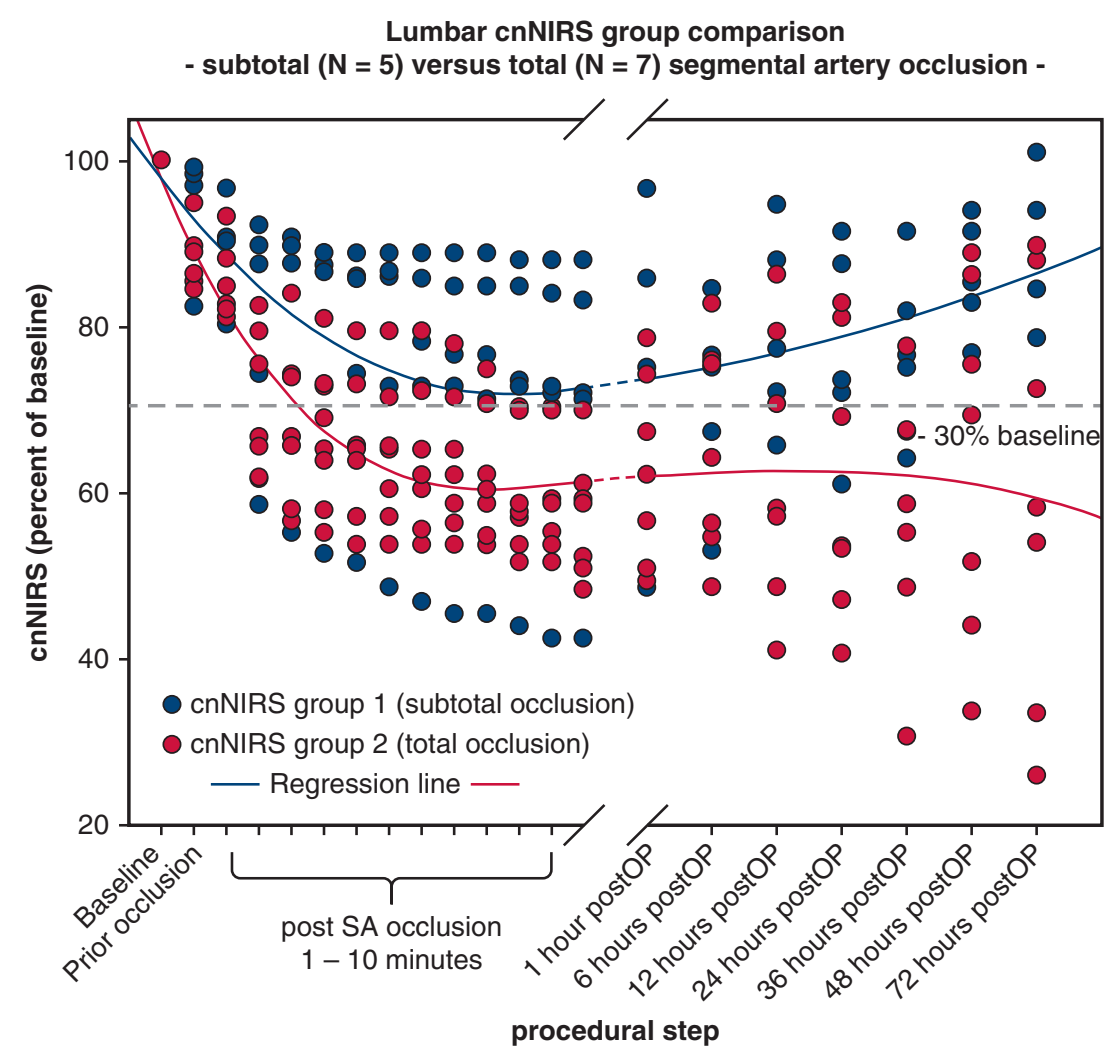

FIGURE 2. Comparison of lumbar cnNIRS measurements between subtotal (blue dots) and total (red dots) SA occlusion. Values gradually digress throughout the postoperative period (represented by the regression lines). The regression line of animals from the subtotal group (blue line) remains above the $30 \%$ cnNIRS threshold. cnNIRS, Collateral network near-infrared spectroscopy; SA, segmental artery. 
differences between groups ranging from $4.4 \% \pm 3.1 \%$ to $6.1 \% \pm 3.9 \%$ during the first 10 minutes. Starting from $89.4 \% \pm 4 \%$ of baseline prior occlusion, cnNIRS in group 2 gradually decreased to $70.5 \% \pm 10 \%, 65.9 \% \pm 9 \%$, and $59.2 \% \pm 8 \%$ at 1,5 , and 10 minutes, respectively $(P<.02)$. After surgery, cnNIRS values increased to $64.3 \% \pm 10 \%$ and $61.8 \% \pm 14 \%$ from 1 to 24 hours, respectively. At 36 hours postoperatively, lumbar cnNIRS demonstrated a decrease to $57.8 \% \pm 15 \%$ baseline before gradually increasing over the remaining surveillance period reaching stable maximum values between $60.5 \% \pm 14 \%$ and $63.2 \% \pm 15 \%$ (Figure 2, group 2/red, and Table E4).

Comparison between subtotal and total segmental artery occlusion. Continuous cnNIRS measurements before SA occlusion did not differ significantly between groups. Postocclusion cnNIRS measurements for the total occlusion group were lower throughout the entire surveillance period compared with the subtotal group, but they did not reach statistical significance until 10 minutes after SA occlusion $(P<.05)$. After 2 days, cnNIRS remained stable in both groups at different oxygenation levels between $86.0 \%$ and $89.0 \% \pm 8 \%$ of baseline for the subtotal and $60.0 \%$ and $63.0 \% \pm 16 \%$ of baseline for the total group, respectively $(P<.05$, Figure 2$)$.

\section{Mean Arterial Blood Pressure Measurements}

Changes in MAP of the entire cohort ranged from 5\% to $7 \%$ of baseline. After surgery, MAP did not demonstrate excessive variations (range, $92 \%-102 \%$ of baseline). Comparison of MAP during and after consecutive SA occlusion reveals no significant difference between subtotal and total occlusion (Figure E1; $P=.314-.899$ ). Correlation analysis among unaltered MAP, cnNIRS, and neurologic outcome was not significantly correlated $(\mathrm{R}=0.1-0.5, P=.227$ .950). During the experiment, MAP was not intentionally altered to minimize its influence on cnNIRS measurements.

\section{Lumbar Collateral Network Near-Infrared Spectroscopy and Neurologic Outcome}

Irrespective of the intervention group, animals that recovered $(\mathrm{N}=8)$ returned to cnNIRS values above $30 \%$ of baseline within the first postoperative hour, whereas animals with permanent paraplegia $(\mathrm{N}=4$, all total occlusion animals) remained below $30 \%$ of baseline throughout the entire surveillance period (Figure 3). Immediately after SA clipping until 10 minutes postocclusion, both recovering and paraplegic animals demonstrated comparable lumbar cnNIRS dynamics with significantly reduced levels compared with baseline $(P=.001$, Table E5). Within 3 days postoperatively, cnNIRS measurements of recovering animals returned to values not significantly different from their individual baseline $(91.4 \% \quad \pm 6 \%$ vs $88.9 \% \pm 9 \%, P=.429)$. However, paraplegic animals' postoperative cnNIRS measurements further decreased relative to their baseline values $(88.5 \% \pm 4 \%$ vs $37.7 \% \pm 14 \%, P=.023$; Table E5).
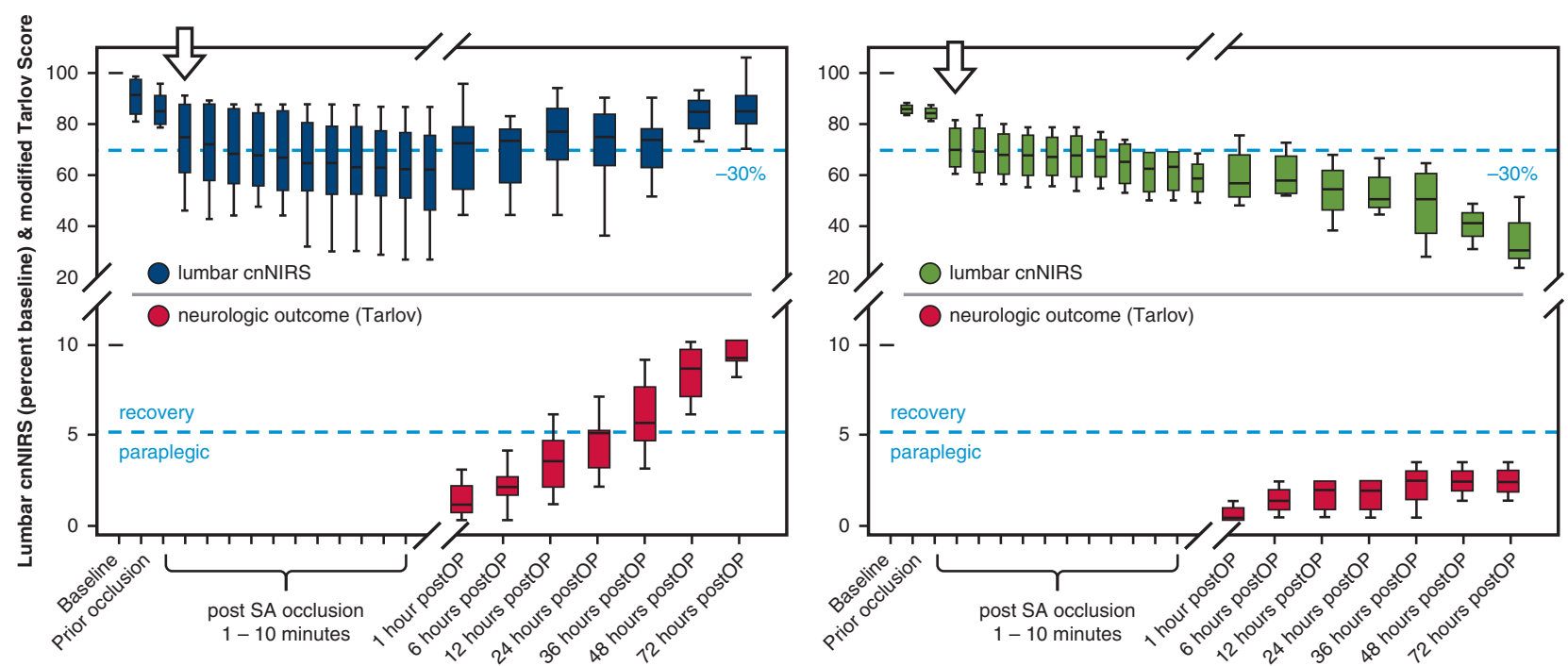

FIGURE 3. cnNIRS is shown throughout the experiment (top) and the postoperative neurologic status (bottom, Tarlov score). Animals that recovered (left, cnNIRS in blue) and animals that remained paraplegic (right, cnNIRS in green). Recovering animals remain above the $30 \%$ cnNIRS threshold throughout the postoperative period (black median line), whereas paraplegic animals remain below the $30 \%$ threshold. cnNIRS, Collateral network near-infrared spectroscopy; $S A$, segmental artery. 
The return of lumbar cnNIRS measurements above $30 \%$ baseline preceded neurologic recovery by approximately 24 to 30 hours. Analysis demonstrates a significant positive correlation between cnNIRS measurements and neurologic outcome as illustrated in Figure $4(\mathrm{R}=0.7, P<.001)$. For clarification, a scatter graph showing individual cnNIRS point data with regard to subtotal versus total occlusion and recovering versus paraplegic animals has been generated (Figure E2).

\section{Histologic Results}

The cervical spinal cord tissue showed no relevant ischemic damage, independent of the intervention group and postoperative neurologic status (Figure 5).

Animals with subtotal occlusion $(\mathrm{N}=5)$ had less severe tissue damage compared with the total occlusion group $(\mathrm{N}=7$; Figure 5, top). Although differences are evident starting from level T3 downward to level L5, statistical significance is reached only for T5 and T8 $(P=.030$ and .045$)$.

Accordingly, because all paraplegic animals were from the total occlusion group $(\mathrm{N}=4)$, mean spinal cord tissue damage was significantly more severe for paraplegic animals compared with animals that recovered (0-4.3, range, $0-8$ vs $0-1.9$, range, $0-5 ; P<.001$; Figure 5 , bottom).

\section{DISCUSSION}

The presented experiment showed for the first time that lumbar cnNIRS reacts to selective SA occlusion and is capable of differentiating between a subtotal and a total occlusion pattern. Furthermore, evaluation of cnNIRS and neurologic outcome revealed significant positive correlation. Although an exact cutoff value for cnNIRS regarding SCI could not be determined, animals that remained paraplegic had consistent mean cnNIRS values lower than $30 \%$ of baseline, whereas animals that recovered returned to levels above $30 \%$ of baseline within the first postoperative hour. A short synoptic perspective statement is provided in Video 1.

\section{Demand for Noninvasive Monitoring}

With the recently introduced endovascular procedure for paraplegia prevention by means of staged $\mathrm{CN}$ preconditioning through $\mathrm{MIS}^{2} \mathrm{ACE},{ }^{14,18}$ and a general trend toward more extensive endovascular aortic procedures, noninvasive

- postoperative cnNIRS and neurological outcome -

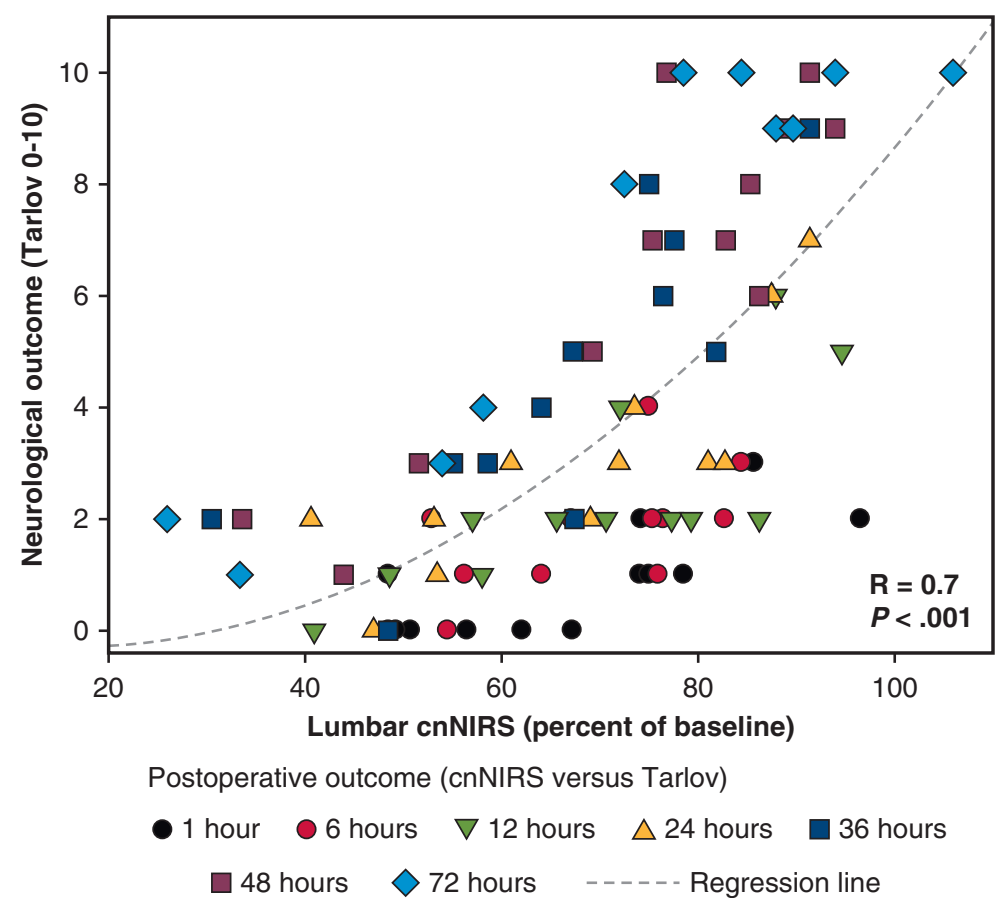

FIGURE 4. Correlation graph for cnNIRS and neurologic outcome. Values are depicted for each animal at each postoperative time point $(\mathrm{N}=12$, starting 1 hour postoperatively) showing a significant positive correlation. Different time points are color coded demonstrating the association between recovering animals and higher cnNIRS ratios after 24 hours. High cnNIRS values associated with low Tarlov scores are exclusively measurements within the first 24 postoperative hours, when "temporary" paraplegia was present in all animals. It is demonstrated that high Tarlov scores ( $>5)$ are not associated with low cnNIRS measurements ( $<30 \%$ of baseline). cnNIRS, Collateral network near-infrared spectroscopy. 

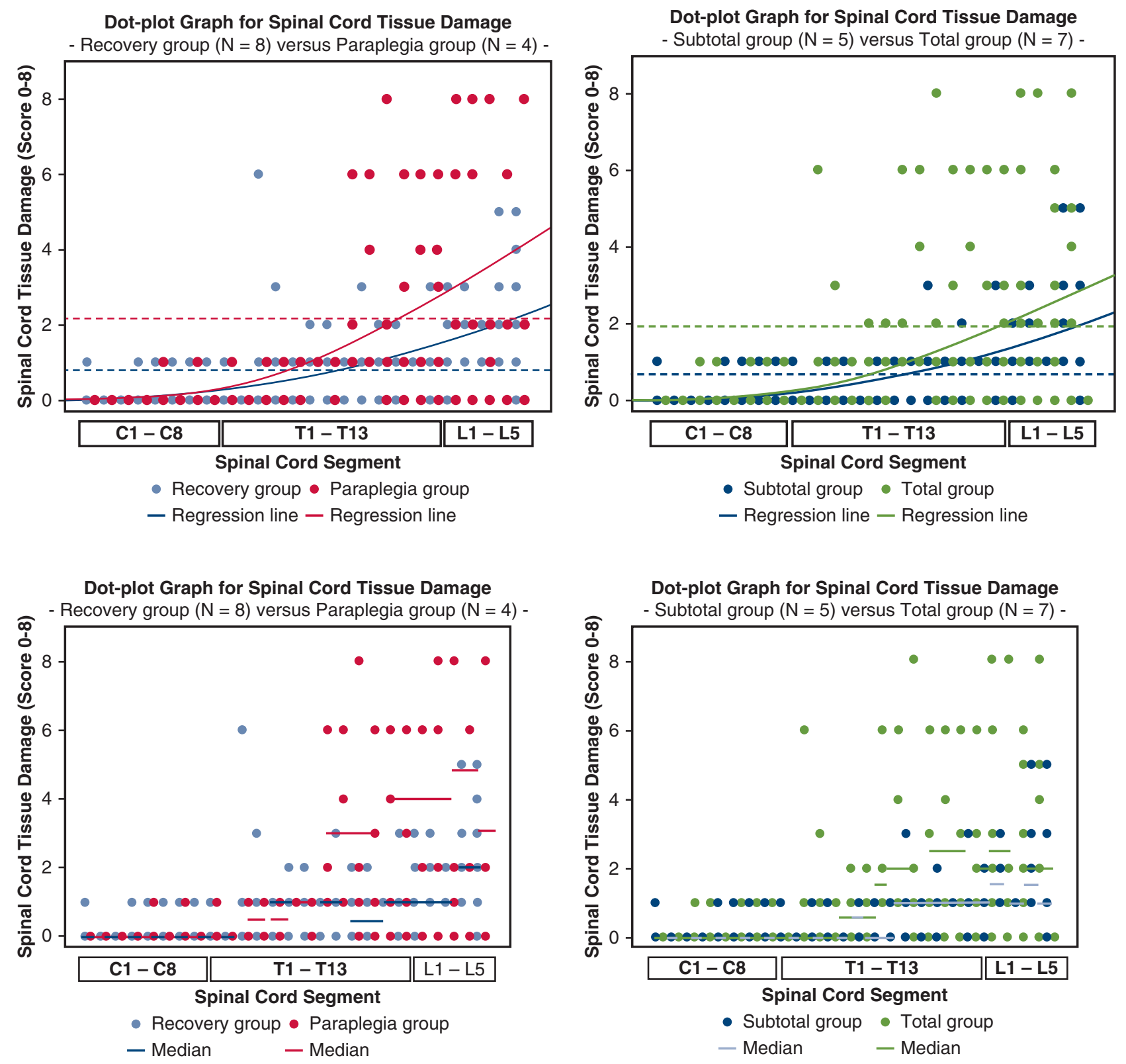

FIGURE 5. Degree of histopathologic spinal cord damage; (left) comparing recovering $(\mathrm{N}=8$, blue) and paraplegic $(\mathrm{N}=4$, red $)$ animals; (right) comparison between subtotal $(\mathrm{N}=5$, blue $)$ and total $(\mathrm{N}=7$, green $) \mathrm{SA}$ occlusion. Each colored dot represents a spinal cord tissue sample $($ cervical $=\mathrm{C}$; thoracic $=\mathrm{T}$, and lumbar $=\mathrm{L}$ ) with a horizontal line showing the median value according to a tissue damage scoring system from 0 (no damage) to 8 (severe damage). It is noticeable that cord damage of the lower thoracic and lumbar region is more severe in paraplegic animals (left, red) and after total SA occlusion (right, green) compared with recovering animals and those receiving subtotal occlusion, respectively.

monitoring methods depicting real-time spinal cord perfusion/oxygenation become all the more essential.

\section{Previous Experience With Collateral Network Near- Infrared Spectroscopy}

Previous experimental and clinical studies on cnNIRS have shown that although in heterogeneous setups and study protocols, it reflects oxygenation changes after aortic crossclamping and distal aortic perfusion in real-time. , $^{7,11-13,20}$
On the basis of these and other studies, cnNIRS emerged as a promising new and economic method, potentially guiding extensive aortic procedures by giving real-time feedback on spinal cord perfusion. ${ }^{21}$

\section{Sensitivity of Collateral Network Near-Infrared Spectroscopy to Segmental Artery Occlusion}

Lumbar cnNIRS reacted to acute interruption of proximal SA perfusion; however, lumbar cnNIRS first started 


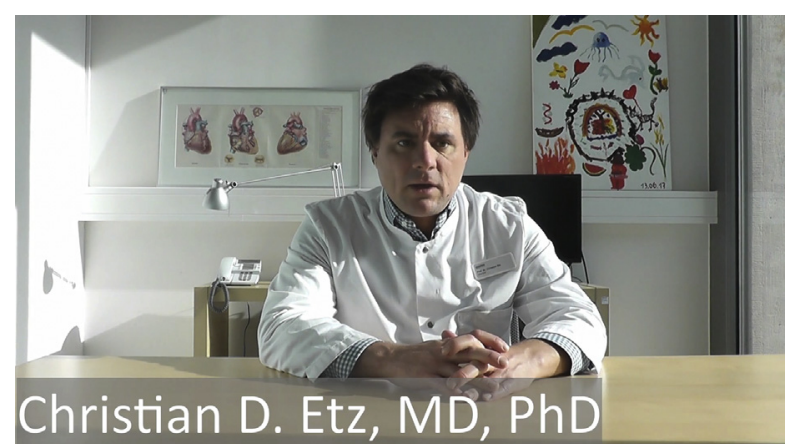

VIDEO 1. Short background, conclusion, and perspective statement by the senior author. Video available at: https://www.jtcvs.org/article/S00225223(18)33255-0/fulltext.

to decrease once the lower thoracic/lumbar SA inflow was occluded, demonstrating a less severe decrease in measurements with patent lower thoracic SAs. Whether SA occlusion by means of stent-graft implantation or MIS ${ }^{2} \mathrm{ACE}$ of only a limited number of arteries can be depicted by lumbar cnNIRS remains to be evaluated. After serial SA occlusion, cnNIRS signals of recovering animals consistently increased throughout the surveillance period, which is in accordance with previous clinical reports and experiments. $^{2,10,16,22}$ Moerman and colleagues ${ }^{22}$ demonstrated an immediate linear correlation of cnNIRS and arterial blood pressure after regional SA inflow interruption. However, this linear cnNIRS dependency on arterial blood pressure was not demonstrated in the present study, because no animal experienced relevant blood pressure alterations.

In an early experiment on spinal cord NIRS monitoring by LeMaire and colleagues, ${ }^{7}$ sequential ligation of segmental arteries from T6-L1 led to a prominent decrease at the lower thoracic level (T9-T11). These were significantly lower than measurements from the upper cord (T6-T7), showing a decrease of only $6.3 \%$ of baseline (upper cord) compared with $39 \%$ (lower cord, $P=.026$ ). These findings are consistent with recent studies $^{11,12}$ attributing the measurement stability of the upper thoracic region to the collateralization via the subclavian/internal thoracic arteries. Whether in addition to lumbar cnNIRS optodes, mid and especially lower thoracic cnNIRS measurements also are necessary for a complete and consistent oxygenation mapping of the $\mathrm{CN}$ is yet unclear and is the focus of ongoing research. The limitation of optode placement directly above the vertebrae has been acknowledged by their respective authors, who suggested that measuring surrounding tissue may enable indirect cord monitoring via the paraspinal $\mathrm{CN},{ }^{7,20,23}$ a concept that represents the rationale for current cnNIRS monitoring practice. ${ }^{11,12,23}$

Although sensitivity of cnNIRS after stent deployment during endovascular aortic repair was recently published in 2 reports (total of 3 patients), ${ }^{21,22}$ available data from previous case series and ongoing clinical investigations suggest that lumbar cnNIRS does not reliably pick up relevant changes in oxygenation during endovascular procedures in humans (not experiencing procedure-related SCI). ${ }^{11,24}$ It is important to note that optode positioning in the aforementioned case reports was at the lower thoracic level (T9-T11), whereas optodes in current clinical investigations are placed bilaterally at the lumbar level (L1-L3).

The presented study demonstrates that cnNIRS is capable of reflecting $\mathrm{CN}$ oxygenation in real-time after selective $\mathrm{SA}$ occlusion, also differentiating between complete SA interruption and patency of 2 SA pairs. Nevertheless, the threshold of critical SA sacrifice necessary to be detected by cnNIRS in humans remains unclear. Whether patients exhibiting stable cnNIRS signals also have sufficient perfusion to maintain adequate spinal cord tissue oxygenation, directly via intraspinal collaterals or indirectly via the paraspinal $\mathrm{CN},{ }^{10,25}$ needs to be further investigated.

\section{The Conundrum of Segmental Artery Patency}

Patency of 2 pairs of segmental arteries led to higher cnNIRS signals and expectably less spinal cord tissue damage with accelerated neurologic recovery. The rationale of maintaining perfusion via the lowest thoracic segmental arteries was mainly chosen on the basis of previous studies, demonstrating that this region exhibits the most distinct spinal cord tissue damage after consecutive SA sacrifice. ${ }^{16,18}$ These findings are consistent with the results of the presented study (most pronounced SCI between thoracic level 8 and lumbar level 2). ${ }^{16,18}$ This boundary zoneranging from $\mathrm{T} 9 / 10$ to $\mathrm{L} 2 / 3$ - seems to represent the most vulnerable region for ischemic tissue damage. The favorable clinical outcome and less severe spinal cord tissue damage of animals with patent $\mathrm{CN}$ inflow to this region underscore this theory, also emphasizing the clinical potential of real-time cnNIRS.

During recent years, clinical studies have divided the aortic community. ${ }^{26-28}$ Although it becomes more and more apparent that SA reimplantation during open aortic repair does not provide absolute safety, it may offer some protection against postoperative hemodynamic instabilities. With regard to SCI protection, however, this topic remains highly debated among experts.

At first glance, it may seem that the presented results are in favor of surgical SA reimplantation. However, it is important to emphasize the fundamental differences in clinical SA reimplantation. In this experiment, no aortic crossclamping, SA ostia opening, or time-consuming surgical reimplantation was performed. Therefore, disadvantageous effects of reimplantation that may potentially mitigate adequate preconditioning, such as back-bleeding with steal from the $\mathrm{CN}$ or subsequent thrombotic SA occlusion after reimplantation, did not occur. Rather than SA reimplantation, the presented experimental set-up corresponds to a 
lopsided, open-staged procedure for $\mathrm{CN}$ preconditioning. On the basis of these observations, 2 different future experimental and clinical approaches may be considered. Either (1) SAs of the lower thoracic/upper lumbar region should be spared during a first MIS $^{2} \mathrm{ACE}$ session to ensure potential superior neurologic integrity or (2) exclusively this region should be occluded first, thereby potentially facilitating a more pronounced stimulus for $\mathrm{CN}$ preconditioning and adequate spinal cord ischemia prophylaxis.

\section{Clinical Implications and Future Perspectives}

The presented findings underscore the potential of lumbar cnNIRS to be a clinically applicable and easy-to-use real-time monitoring modality particularly during the early postoperative period. Of note, all animals that recovered neurologically managed to reestablish cnNIRS oxygenation values above $30 \%$ of baseline within 1 hour postoperatively. Whether the predictive value of cnNIRS for neurologic recovery depends on such an oxygenation threshold (eg, $30 \%$ of baseline) or is time-dependent (eg, oxygenation recovery within 1 hour postocclusion) cannot be answered conclusively at this point. For clinical practice, however, the demonstrated correlation with neurologic recovery is encouraging, because it is especially important for sedated patients with prolonged ventilation, for whom the risk of delayed paraplegia during the postoperative period seems the greatest. ${ }^{29}$ The fact that lumbar cnNIRS depicted oxygenation changes in the $\mathrm{CN}$ over a course of 3 days, potentially reflecting the $\mathrm{CN}$ collateralization process, also warrants further clinical and experimental investigation.

\section{Study Limitations}

Because of anatomic and physiologic differences between species (pigs and humans), conclusions drawn from any translational experimental research should be interpreted with caution. When assessing regional tissue oxygenation via cnNIRS, the emitted light penetrates through the paraspinal vasculature/muscles, averaging measurements over the entire area in its optical path. In pigs, the deep paraspinal muscles are arranged in a mainly sagittal, rather than transversal manner; thus, a longitudinally placed optode on a 45-kg pig always measures a larger portion of the $\mathrm{CN}$ compared with an average human adult. Yet, this difference may be solved by using larger animals or measuring/averaging values of an equally large portion of the human $\mathrm{CN}$ (eg, by placement of additional optodes).

\section{CONCLUSIONS}

Lumbar cnNIRS reacts to occlusion of segmental arteries in real time and correlates with neurologic outcome. Patency of 2-nonreimplanted-pairs of segmental arteries of the lower thoracic region results in a less pronounced lumbar cnNIRS decrease, potentially facilitating maintenance of sufficient spinal cord perfusion. This preliminary data suggests that cnNIRS may be a valuable noninvasive tool for detecting imminent spinal cord ischemia during and after aortic procedures involving segmental artery occlusion. Further in-depth analyses are warranted to determine the exact threshold for imminent spinal cord injury with regard to absolute cnNIRS values.

\section{Conflict of Interest Statement}

Authors have nothing to disclose with regard to commercial support.

\section{References}

1. Koeppel TA, GA, Jacobs MJ. DGG Leitlinie-Thorakale und Thorakoabdominelle Aortenaneurysmen. Europäisches Gefäßzentrum Aachen-Maastricht; 2010. Available at: http://www.gefaesschirurgie.de/fileadmin/websites/dgg/download/ LL_DTAA_und_TAAA_2011.pdf.

2. Etz CD, Luehr M, Kari FA, Bodian CA, Smego D, Plestis KA, et al. Paraplegia after extensive thoracic and thoracoabdominal aortic aneurysm repair: does critical spinal cord ischemia occur postoperatively? J Thorac Cardiovasc Surg. 2008;135:324-30.

3. Panthee N, Ono M. Spinal cord injury following thoracic and thoracoabdominal aortic repairs. Asian Cardiovasc Thorac Ann. 2015;23:235-46.

4. National Spinal Cord Injury Statistical Center. Spinal cord injury facts and figures at a glance. J Spinal Cord Med. 2013;36:1-2.

5. Pillai JB, Pellet Y, Panagopoulos G, Sadek MA, Abjigitova D, Weiss D, et al. Somatosensory-evoked potential-guided intercostal artery reimplantation in thoracoabdominal aortic aneurysm surgery. Innovations (Phila). 2013;8:302-6.

6. Dias-Neto M, Reis PV, Rolim D, Ramos JF, Teixeira JF, Sampaio S, et al. Strategies to prevent TEVAR-related spinal cord ischemia. Vascular. 2017;25: 307-15.

7. LeMaire SA, Ochoa LN, Conklin LD, Widman RA, Clubb FJ Jr, Undar A, et al. Transcutaneous near-infrared spectroscopy for detection of regional spinal ischemia during intercostal artery ligation: preliminary experimental results. J Thorac Cardiovasc Surg. 2006;132:1150-5.

8. Demir A, Erdemli O, Unal U, Tasoglu I. Near-infrared spectroscopy monitoring of the spinal cord during type B aortic dissection surgery. J Card Surg. 2013;28: 291-4.

9. Etz CD, Kari FA, Mueller CS, Silovitz D, Brenner RM, Lin HM, et al. The collateral network concept: a reassessment of the anatomy of spinal cord perfusion. J Thorac Cardiovasc Surg. 2011;141:1020-8.

10. Etz CD, Kari FA, Mueller CS, Brenner RM, Lin HM, Griepp RB, et al. The collateral network concept: remodeling of the arterial collateral network after experimental segmental artery sacrifice. J Thorac Cardiovasc Surg. 2011;141:1029-36.

11. Etz CD, von Aspern K, Gudehus S, Luehr M, Girrbach FF, Ender J, et al. Nearinfrared spectroscopy monitoring of the collateral network prior to, during, and after thoracoabdominal aortic repair: a pilot study. Eur J Vasc Endovasc Surg. 2013;46:651-6.

12. von Aspern K, Haunschild J, Hoyer A, Luehr M, Bakhtiary F, Misfeld M, et al. Non-invasive spinal cord oxygenation monitoring: validating collateral network near-infrared spectroscopy for thoracoabdominal aortic aneurysm repair. Eur $J$ Cardiothorac Surg. 2016;50:675-83.

13. Boezeman RP, van Dongen EP, Morshuis WJ, Sonker U, Boezeman EH, Waanders FG, et al. Spinal near-infrared spectroscopy measurements during and after thoracoabdominal aortic aneurysm repair: a pilot study. Ann Thorac Surg. 2015;99:1267-74.

14. Etz CD, Debus ES, Mohr FW, Kolbel T. First-in-man endovascular preconditioning of the paraspinal collateral network by segmental artery coil embolization to prevent ischemic spinal cord injury. J Thorac Cardiovasc Surg. 2015;149: 1074-9.

15. Von Aspern K, Luehr M, Mohr FW, Etz CD. Spinal cord protection in open- and endovascular thoracoabdominal aortic aneurysm repair: critical review of current concepts and future perspectives. J Cardiovasc Surg (Torino). 2015;56:745-9.

16. Etz CD, Homann TM, Luehr M, Kari FA, Weisz DJ, Kleinman G, et al. Spinal cord blood flow and ischemic injury after experimental sacrifice of thoracic and abdominal segmental arteries. Eur J Cardiothorac Surg. 2008;33:1030-8. 
17. Guide for the Care and Use of Laboratory Animals. 8th ed. Washington, DC: The National Academies Press; 2011.

18. Geisbusch S, Stefanovic A, Koruth JS, Lin HM, Morgello S, Weisz DJ, et al. En dovascular coil embolization of segmental arteries prevents paraplegia after subsequent thoracoabdominal aneurysm repair: an experimental model. J Thorac Cardiovasc Surg. 2014;147:220-6.

19. Bischoff MS, Scheumann J, Brenner RM, Ladage D, Bodian CA, Kleinman G, et al. Staged approach prevents spinal cord injury in hybrid surgicalendovascular thoracoabdominal aortic aneurysm repair: an experimental model. Ann Thorac Surg. 2011;92:138-46.

20. Suehiro K, Funao T, Fujimoto Y, Mukai A, Nakamura M, Nishikawa K, et al. Transcutaneous near-infrared spectroscopy for monitoring spinal cord ischemia: an experimental study in swine. J Clin Monit Comput. 2017;31:975-9.

21. Badner NH, Nicolaou G, Clarke CF, Forbes TL. Use of spinal near-infrared spectroscopy for monitoring spinal cord perfusion during endovascular thoracic aortic repairs. J Cardiothorac Vasc Anesth. 2011;25:316-9.

22. Moerman A, Van Herzeele I, Vanpeteghem C, Vermassen F, Francois K, Wouters P, et al. Near-infrared spectroscopy for monitoring spinal cord ischemia during hybrid thoracoabdominal aortic aneurysm repair. J Endovasc Ther. 2011;18:91-5.

23. Luehr M, von Aspern K, Etz CD. Limitations of direct regional spinal cord monitoring using near-infrared spectroscopy: indirect paraspinal collateral network surveillance is the answer! Ann Thorac Surg. 2016;101:1238-9.

24. von Aspern K, Bakhtiary F, Misfeld M, Mohr FW, Etz CD. Indirect monitoring of spinal cord oxygenation by paraspinal near-infrared spectroscopy.
Experimental and clinical data (Article in German). Gefässchirurgie. 2017; 22:102-9.

25. Kari FA, Beyersdorf F. Aortic surgery and spinal collateral flow: a call for structured approaches to functional characterization of the intraspinal collateral system. J Thorac Cardiovasc Surg. 2015;149:1675-80.

26. David N, Roux N, Douvrin F, Clavier E, Bessou JP, Plissonnier D, et al. Aortic aneurysm surgery: long-term patency of the reimplanted intercostal arteries. Ann Vasc Surg. 2012;2012:839-44.

27. Etz CD, Halstead JC, Spielvogel D, Shahani R, Lazala R, Homann TM, et al. Thoracic and thoracoabdominal aneurysm repair: is reimplantation of spinal cord arteries a waste of time? Ann Thorac Surg. 2006;82:1670-7.

28. Wynn M, Acher C, Marks E, Acher CW. The effect of intercostal artery reimplantation on spinal cord injury in thoracoabdominal aortic aneurysm surgery. $J$ Vasc Surg. 2016;64:289-96.

29. Estrera AL, Sheinbaum R, Miller CC, Azizzadeh A, Walkes JC, Lee TY, et al. Cerebrospinal fluid drainage during thoracic aortic repair: safety and current management. Ann Thorac Surg. 2009;88:9-15.

Key Words: collateral network near-infrared spectroscopy, minimally invasive segmental artery coil and plug embolization, spinal cord protection, thoracoabdominal aortic aneurysm repair 


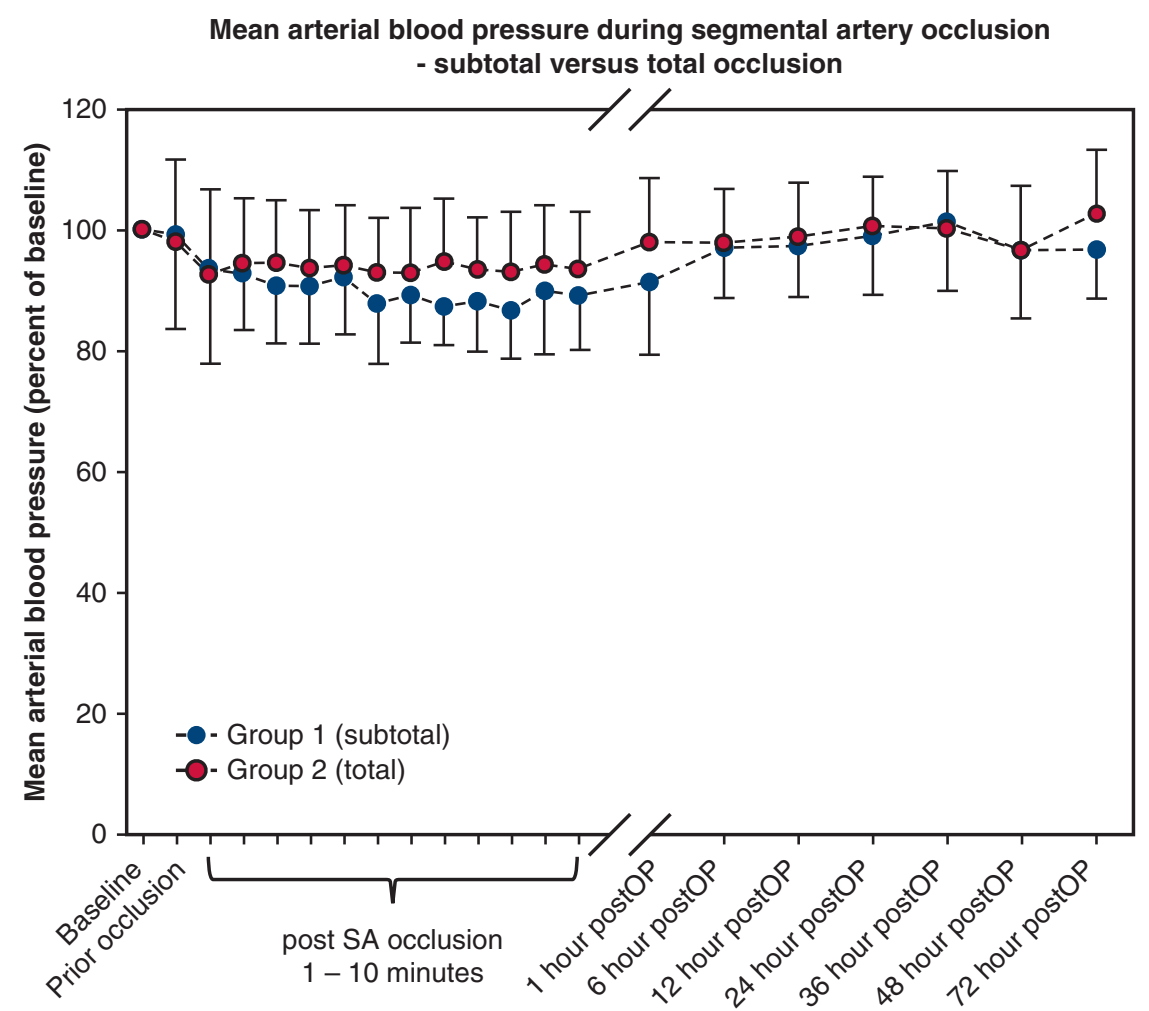

FIGURE E1. The invasive mean arterial blood pressures throughout the experiment are shown (subtotal, $\mathrm{N}=5$ in $b l u e$, versus total, $\mathrm{N}=7$ in $r e d$ ). No significant differences throughout the experiment and in-between groups can be shown. $S A$, Segmental artery.

Lumbar cnNIRS group comparison

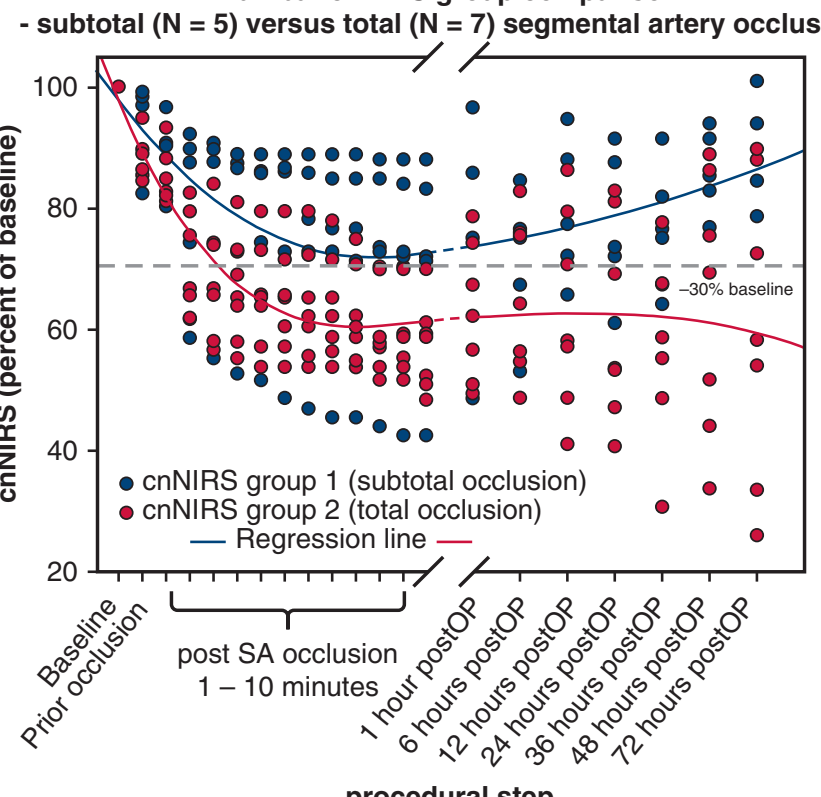

Lumbar cnNIRS group comparison - Recovery $(\mathrm{N}=8)$ versus paraplegia $(\mathrm{N}=4)$ -

procedural step

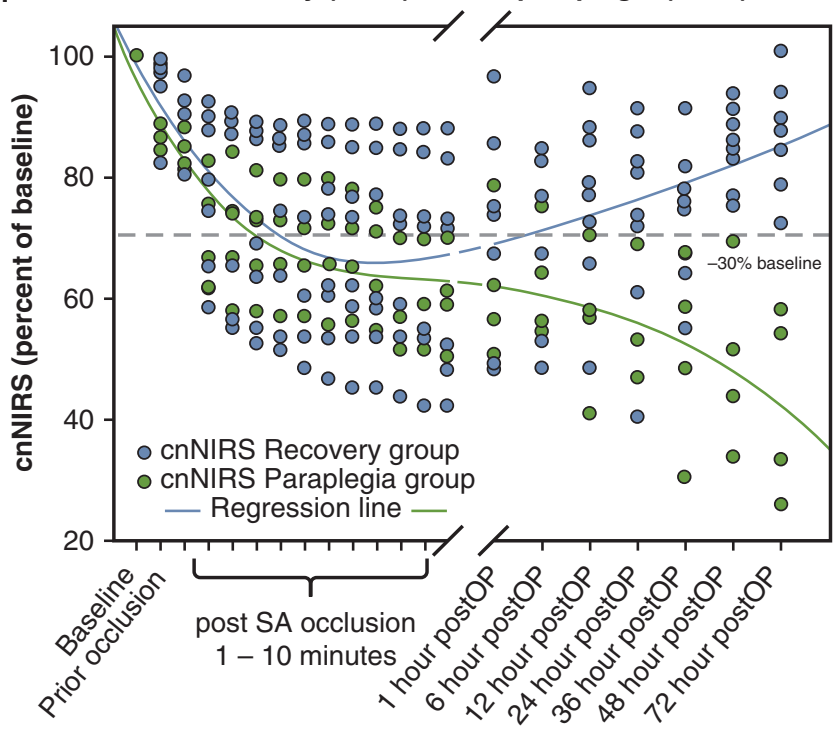

procedural step

FIGURE E2. Individual data points for lumbar cnNIRS. Left: Scatter plot showing cnNIRS throughout the experiment comparing subtotal occlusion (blue dots and blue regression line) and total occlusion (red dots and red regression line). Right: Comparison between cnNIRS measurements for recovering animals (blue dots and blue regression line) and paraplegic animals (green dots and green regression line). Recovering and paraplegic animals seem to have substantial overlap intraoperatively. Values gradually digress throughout the postoperative period (represented by the regression lines). cnNIRS, Collateral network near-infrared spectroscopy; $S A$, segmental artery. 
TABLE E1. Neurologic assessment (modified Tarlov score)

\begin{tabular}{ll}
\hline \multicolumn{1}{c}{ Modified Tarlov score } \\
\hline Score & \multicolumn{1}{c}{ Description } \\
\hline 0 & No voluntary movements \\
\hline 1 & Perceptible movements at joints \\
\hline 2 & Good movements at joints but inability to stand \\
\hline 3 & Ability to get up with assistance but no ability to stand \\
\hline 4 & Ability to get up with assistance and stand with assistance \\
\hline 5 & Ability to get up with assistance and stand unassisted \\
\hline 6 & Ability to get up and stand unassisted $<1$ min \\
\hline 7 & Ability to get up and stand unassisted $>1$ min \\
\hline 8 & Ability to walk $<1$ min \\
9 & Ability to walk $>1$ min \\
10 & Complete recovery \\
\hline
\end{tabular}


TABLE E2. Ischemic spinal cord damage score with example images

\begin{tabular}{|c|c|c|}
\hline Score & Definition & Image \\
\hline 0 & No apparent necrosis & \\
\hline 1 & Necrosis of single (motor) neurons only & \\
\hline 2 & Necrosis of 1 posterior horn only & \\
\hline 3 & Necrosis of both posterior horns only & $\longmapsto$ \\
\hline 4 & Necrosis of both posterior horns/surrounding white matter & \\
\hline 5 & Necrosis of both anterior horns only & \\
\hline 6 & Central necrosis (posterior/anterior horns/parts of white matter) & $\stackrel{\text { mosim }}{\longmapsto}$ \\
\hline 7 & Complete necrosis of grey matter only & \\
\hline 8 & Complete necrosis of the whole section & \\
\hline
\end{tabular}


TABLE E3. Adverse events other than paraplegia

\begin{tabular}{|c|c|}
\hline \multicolumn{2}{|r|}{ Adverse events during the experiment } \\
\hline $\begin{array}{l}\text { Postoperative } \\
\text { day }\end{array}$ & Description \\
\hline 0 & $\begin{array}{c}\text { Intraoperative aortic laceration located in between } 2 \\
\text { SAs with need for subsequent ligation }(\mathrm{N}=1)\end{array}$ \\
\hline $0-1$ & Temporary difficulties in micturition $(\mathrm{N}=3)$ \\
\hline $0-3$ & $\begin{array}{l}\text { Neurogenic bladder syndrome with overflow } \\
\text { incontinence }(\mathrm{N}=2 \text {, paraplegic animals only) }\end{array}$ \\
\hline 3 & $\begin{array}{l}\text { Mild to moderate pleuritis (incidental autopsy } \\
\text { finding), normal oxygenation and behavior } \\
(\mathrm{N}=2)\end{array}$ \\
\hline 3 & $\begin{array}{l}\text { Pleural effusion not affecting breathing or general } \\
\text { health condition (incidental autopsy finding, } \\
\mathrm{N}=4 \text { ) }\end{array}$ \\
\hline
\end{tabular}

SA, Segmental artery.

TABLE E4. Lumbar collateral network near-infrared spectroscopy measurements for intervention groups (subtotal and total occlusion)

\begin{tabular}{|c|c|c|c|c|c|c|}
\hline \multirow[b]{2}{*}{ Procedural step } & \multicolumn{3}{|c|}{ Group 1 (subtotal, $\mathbf{N}=5$ ) } & \multicolumn{3}{|c|}{ Group 2 (total, $N=7)$} \\
\hline & cnNIRS & cnNIRS $(\%)$ & MAP & cnNIRS & cnNIRS (\%) & MAP \\
\hline Preoperative baseline & $62.4 \pm 5$ & 100 & $70.8 \pm 7$ & $62.5 \pm 4$ & 100 & $67.2 \pm 4$ \\
\hline Prior SA occlusion & $57.3 \pm 4$ & $92.3 \pm 8$ & $67.0 \pm 4$ & $55.5 \pm 2$ & $89.4 \pm 4$ & $67.6 \pm 4$ \\
\hline Thoracic SA occlusion & $54.7 \pm 4$ & $88.1 \pm 7$ & $63.2 \pm 4$ & $53.9 \pm 3$ & $86.3 \pm 5$ & $64.0 \pm 6$ \\
\hline Lumbar SA occlusion & $48.6 \pm 9$ & $78.3 \pm 11$ & $63.6 \pm 4$ & $45.3 \pm 5$ & $72.7 \pm 10$ & $65.0 \pm 3$ \\
\hline 1 min postocclusion & $48.3 \pm 9$ & $77.8 \pm 11$ & $62.0 \pm 4$ & $43.9 \pm 6$ & $70.5 \pm 10$ & $65.4 \pm 2$ \\
\hline 5 min postocclusion & $44.9 \pm 9$ & $72.4 \pm 11$ & $60.8 \pm 4$ & $41.1 \pm 6$ & $65.9 \pm 9$ & $64.4 \pm 3$ \\
\hline 10 min postocclusion & $43.0 \pm 10$ & $69.3 \pm 14$ & $61.2 \pm 3$ & $36.9 \pm 5$ & $59.2 \pm 8$ & $64.6 \pm 3$ \\
\hline 60 min postocclusion & $47.2 \pm 8$ & $76.0 \pm 10$ & $63.0 \pm 5$ & $39.8 \pm 5$ & $64.3 \pm 10$ & $67.8 \pm 4$ \\
\hline $12 \mathrm{~h}$ postocclusion & $49.4 \pm 5$ & $79.5 \pm 10$ & $66.4 \pm 3$ & $39.3 \pm 6$ & $63.6 \pm 13$ & $68.4 \pm 3$ \\
\hline $24 \mathrm{~h}$ postocclusion & $47.7 \pm 5$ & $76.8 \pm 9$ & $67.8 \pm 2$ & $38.1 \pm 6$ & $61.8 \pm 13$ & $69.4 \pm 2$ \\
\hline $48 \mathrm{~h}$ postocclusion & $53.4 \pm 4$ & $86.0 \pm 6$ & $65.2 \pm 2$ & $39.5 \pm 9$ & $63.2 \pm 15$ & $68.7 \pm 1$ \\
\hline $72 \mathrm{~h}$ postocclusion & $55.6 \pm 7$ & $89.5 \pm 9$ & $65.0 \pm 3$ & $37.7 \pm 9$ & $60.5 \pm 16$ & $72.4 \pm 3$ \\
\hline
\end{tabular}

cnNIRS, Collateral network near-infrared spectroscopy; MAP, mean arterial pressure; SA, segmental artery. 
TABLE E5. Lumbar collateral network near-infrared spectroscopy measurements for recovering and paraplegic and group comparisons

\begin{tabular}{|c|c|c|c|c|c|c|}
\hline \multirow[b]{2}{*}{ Procedural step } & \multicolumn{3}{|c|}{ Recovery group $(\mathbf{N}=\mathbf{8})$} & \multicolumn{3}{|c|}{ Paraplegic group $(N=4)$} \\
\hline & cnNIRS & cnNIRS (\%) & МАP & cnNIRS & cnNIRS $(\%)$ & MAP \\
\hline Preoperative baseline & $62.1 \pm 5$ & 100 & $70.5 \pm 5$ & $63.1 \pm 3$ & 100 & $63 \pm 2$ \\
\hline Prior SA occlusion & $56.5 \pm 3$ & $91.4 \pm 6$ & $66.6 \pm 4$ & $55.7 \pm 1$ & $88.5 \pm 4$ & $70 \pm 4$ \\
\hline Thoracic SA occlusion & $53.9 \pm 3$ & $87.1 \pm 6$ & $62.2 \pm 4$ & $54.7 \pm 1$ & $86.9 \pm 4$ & $69.5 \pm 4$ \\
\hline Lumbar SA occlusion & $46.2 \pm 6$ & $75.0 \pm 12$ & $63.5 \pm 3$ & $47.2 \pm 5$ & $75.1 \pm 11$ & $67.2 \pm 3$ \\
\hline 1 min postocclusion & $45.0 \pm 7$ & $73.1 \pm 13$ & $62.8 \pm 3$ & $46.3 \pm 6$ & $73.6 \pm 11$ & $67.3 \pm 2$ \\
\hline 5 min postocclusion & $41.3 \pm 6$ & $63.2 \pm 15$ & $61.8 \pm 4$ & $44.2 \pm 5$ & $70.2 \pm 10$ & $66.2 \pm 3$ \\
\hline 10 min postocclusion & $38.8 \pm 9$ & $71.3 \pm 15$ & $62.3 \pm 4$ & $39.5 \pm 4$ & $62.8 \pm 9$ & $65.6 \pm 2$ \\
\hline 60 min postocclusion & $43.8 \pm 7$ & $76.5 \pm 14$ & $64.8 \pm 6$ & $40.6 \pm 6$ & $64.7 \pm 11$ & $67.5 \pm 3$ \\
\hline $12 \mathrm{~h}$ postocclusion & $46.9 \pm 6$ & $73.7 \pm 14$ & $67.5 \pm 4$ & $37.0 \pm 6$ & $59.0 \pm 11$ & $65.5 \pm 2$ \\
\hline $24 \mathrm{~h}$ postocclusion & $45.2 \pm 7$ & $73.7 \pm 14$ & $67.6 \pm 3$ & $36.4 \pm 4$ & $58.0 \pm 9$ & $66.5 \pm 4$ \\
\hline $48 \mathrm{~h}$ postocclusion & $52.8 \pm 5$ & $85.1 \pm 6$ & $66.6 \pm 3$ & $28.0 \pm 5$ & $43.0 \pm 9$ & $70 \pm 3$ \\
\hline $72 \mathrm{~h}$ postocclusion & $55.2 \pm 8$ & $88.9 \pm 9$ & $69.6 \pm 5$ & $24.5 \pm 9$ & $37.7 \pm 14$ & $68 \pm 3$ \\
\hline Procedural step & & cnNIRS (\%) & Mean & & $\mathbf{9 5} \% \mathrm{CI}$ & $P$ value \\
\hline \multicolumn{7}{|c|}{ Comparison: Recovery group } \\
\hline Prior SA occlusion & & $91.4 \pm 6$ & & & & \\
\hline 10 min postocclusion & & $71.3 \pm 15$ & 28. & & $16.3-38.1$ & .001 \\
\hline $72 \mathrm{~h}$ postocclusion & & $88.9 \pm 9$ & & & $-7.2-14.2$ & .429 \\
\hline \multicolumn{7}{|c|}{ Comparison: Paraplegic group } \\
\hline Prior SA occlusion & & $88.5 \pm 4$ & & & & \\
\hline 10 min postocclusion & & $62.8 \pm 9$ & 25. & & $18.8-29.9$ & .001 \\
\hline $72 \mathrm{~h}$ postocclusion & & $37.7 \pm 14$ & 47. & & $9.2-79.5$ & .023 \\
\hline
\end{tabular}

cnNIRS, Collateral network near-infrared spectroscopy; $C I$, confidence interval; $S A$, segmental artery. 